\title{
Psychiatric aspects in Parkinsonism treated with L-dopa
}

\author{
ANTÓNIO R. DAMÁsio, JoÃo LOBO-ANTUNES, AND CARLOS MACEDO \\ From the Department of Psychiatry and Neurology and Centro de Estudos Egas Moniz, Lisbon Faculty of \\ Medicine and the Department of Neurology of the Hospitais Civis de Lisboa, Portugal
}

SUMMARY Psychiatric aspects of patients with Parkinsonism treated with L-dopa are described. These include acute psychosis in patients with or without previous psychiatric illness and worsening or improvement of pre-existing psychiatric conditions. Therapeutic management is discussed The relevance of these studies to the understanding of the psychiatric aspects of Parkinsonism in general is discussed.

The psychiatric aspects of Parkinson's disease have been dealt with to some extent, particularly in the medical literature of the $1930 \mathrm{~s}$ and $1940 \mathrm{~s}$. The attempt to describe a typical disorder of personality has failed. Certain peculiar phenomena have been described in relation to psychological aspects like 'paradoxical akinesia', or the 'blockade of motor performance'. But these are very isolated, elusive, still unexplained phenomena that do not constitute an entity. Apart from this, the emotional and character problems of Parkinsonism are non-specific, and it has been established that no cognitive impairment follows idiopathic Parkinsonism (Mettler and Crandel, 1959; Talland, 1962; Schwab and Zieper, 1965). On the other hand, several psychopathological syndromes may accompany different types of Parkinsonism - for instance, dementia in atherosclerotic Parkinsonism, the behaviour disturbances in post-encephalitic Parkinsonism, and the depressive syndromes that frequently occur with idiopathic Parkinsonism (Waggoner, 1967). The first two conditions are symptomatic of the primary neurological disorders, whereas the latter is predominantly reactive. Any psychiatric syndrome may, of course, coexist with a Parkinsonism syndrome, as an independent entity preceding or following it.

Since the early days of its use as an anti-Parkinsonism agent L-dopa has been known to induce psychic manifestations (Barbeau, 1969; Cotzias, Papavasiliou, and Gellene, 1969; Yahr, Duvoisin, Schear, Barrett, and Hoehn, 1969; Calne, Spiers, Stern, Laurence, and Armitage, 1969; Calne, Stern, Laurence, Sharkey, and Armitage, 1969; McDowell, Lee, Swift, Sweet, Ogsbury, and Kessler, 1970), but only recently have these manifestations been consid- ered relevant to the management of the disease, and studied from a psychiatric viewpoint (Jenkins and Groh, 1970; Damásio, Antunes, and Macedo, 1970; Sacks, Messeloff, Schwartz, Goldfarb, and Kohl, 1970; Celesia and Barr, 1970).

During a trial of L-dopa in Parkinsonism we decided to study our patients from the start from a psychiatric as well as a neurological viewpoint. Ourpurpose was to describe, attempt to interpret and treat the psychopathological situations for which L-dopa has generally been held responsible. In this paper we give an account of the preliminary clinical results.

\section{METHODS}

Forty-eight patients with Parkinsonism were admitted for a trial with L-dopa. According to the diagnostic criteria of Hoehn and Yahr (1967), 40 were of the primary or idiopathic type, and eight of the atherosclerotic type. We excluded any case with the usual limitations posed by the side-effects of L-dopa-namely, severe hypertension, cardiac disease, etc. Cases of acute psychiatric syndromes, including organic brain syndrome, were not considered for trial. The trial was of the open type and the neurological status was evaluated with the Webster scale (Webster, 1968). The results of the neurological study have been published elsewhere (Lobo-Antunes, Macedo, and Damásio, 1970).

On admission there was a careful psychiatric diagnosis based on clinical and psychometric data. Patients were regularly evaluated, and the minimum follow-up period was three months. Depressive patients were also studied with rating scales (Beck rating scale) and were allocated according to a pathogenic classification to three groups: (1) predominantly organic; (2) predominantly endogenous; (3) predominantly reactive. Psychiatric disorders 
were considered to be side-effects of therapy if there was worsening of any pre-existing psychiatric disturbance in the course of treatment, or if any new psychiatric disturbance appeared in a case previously psychiatric or not. Any alteration that was well tolerated by the patient and did not influence the neurological picture was not considered a side-effect and will be described under non-acute psychological changes.

\section{RESULTS}

The Table lists the patients who developed acute or non-acute psychiatric syndromes or worsened preexisting ones. The cases were numbered by order of appearance in a group of 48 patients with Parkinsonism.

There were seven cases of acute disorders and eight cases of non-acute-that is, $31 \%$ of our population of patients. Of these, 13 had a previous psychiatric history $(80 \%)$.

Several cases with past or present psychiatric history did not relapse, worsen, or develop new conditions (three cases of organic psychosis, six cases of reactive depression, and four cases of mixed neurotic troubles). Five cases of reactive depression improved markedly.

The severity of Parkinsonism before treatment and at the time of onset of the psychiatric disturbance is detailed for comparison.

The existence of a psychiatric condition before treatment with L-dopa is obviously an important factor in the determination of new disorders or worsening of existing ones.

In our results idiopathic forms of Parkinsonism seem just as prone to psychiatric troubles as atherosclerotic and post-encephalitic types.

ACUTE DISORDERS There were seven cases of acute psychiatric disorders.

In five cases (nos. $1,2,3,5,12$ ) there was a confusional syndrome of sudden onset with delirium, moderate agitation, intense anxiety, and depressive humour. There were always visual hallucinatory phenomena. All patients except case 1, had a past psychiatric history In the prodromal phase insomnia always occurred at least in the 24 hours before the episode along with a significant increase of anxiety. Apart from case 5, the period of disorientation did not last for more than a day. All cases were immediately given tranquillizers and the dose of L-dopa was sharply reduced or it was stopped. The reorganization of the sensorium cleared the psychosis.

The acute phase of case 5 lasted four days. The clinical picture started at a dose of $5 \mathrm{~g}$ per day of L-dopa, but it tended to oscillate according to a daynight cycle, slightly improving in daytime. The content of hallucinations was terrifying, with strong paranoid features. It was necessary to administer neuroleptics. The patient was a 54 year old man with

TA BLE

CLINICAL DETAILS

\begin{tabular}{|c|c|c|c|c|c|c|c|c|c|c|c|}
\hline $\begin{array}{l}\text { Patient } \\
\text { no. }\end{array}$ & $\begin{array}{c}\text { Type of } \\
\text { Parkinsonism }\end{array}$ & $\operatorname{Sex}$ & $\begin{array}{l}\text { Age } \\
(y r .)\end{array}$ & $\begin{array}{l}\text { Diration } \\
(y r .)\end{array}$ & Operation & $\begin{array}{l}\text { Initial } \\
\text { Webster } \\
\text { score }\end{array}$ & $\begin{array}{l}\text { Webster } \\
\text { score at } \\
\text { time of } \\
\text { disturbance }\end{array}$ & $\begin{array}{l}\text { L-dopa } \\
\text { dosage } \\
(g / d .)^{*}\end{array}$ & $\begin{array}{l}\text { Previous } \\
\text { psychiatric } \\
\text { history }\end{array}$ & Psychiatric syndromes & $\begin{array}{l}\text { Psychiat. } \\
\text { drugs } !\end{array}$ \\
\hline 1 & Idiopathic & $\mathbf{F}$ & 77 & 10 & - & 19,5 & 4 & 3 & - & Acute confusional & $\mathbf{P}$ \\
\hline 2 & Idiopathic & $\mathbf{M}$ & 69 & 14 & + & 15 & 18 & 5 & + & Acute confusional & $\mathrm{IM} / \mathrm{DZ}$ \\
\hline 3 & Idiopathic & $\mathbf{M}$ & 59 & 33 & + & 27 & 25 & 4,5 & + & Acute confusional & $\mathrm{DZ}$ \\
\hline 4 & Idiopathic & $\mathbf{M}$ & 68 & 29 & - & 19,5 & 18,5 & 4,5 & + & Acute depressive & NT/DZ \\
\hline 5 & Idiopathic & $\mathbf{M}$ & 54 & 10 & - & 23 & 6 & 5 & + & $\begin{array}{l}\text { Acute confusional/ } \\
\text { severe endogenous } \\
\text { depression }\end{array}$ & $\begin{array}{l}\text { AT/DZ } \\
\text { TH }\end{array}$ \\
\hline 6 & Idiopathic & $\mathbf{F}$ & 73 & 10 & - & 19,5 & 6,5 & 3,5 & + & $\begin{array}{l}\text { Worsening of reactive } \\
\text { depression }\end{array}$ & IM/DZ \\
\hline 7 & Atherosclerotic & $\mathbf{M}$ & 57 & 1 & - & 9 & 4 & 5 & + & $\begin{array}{l}\text { Worsening of organic } \\
\text { depression }\end{array}$ & $\mathrm{IM} / \mathrm{DZ}$ \\
\hline 8 & Idiopathic & $\mathbf{M}$ & 50 & 6 & - & 15 & 2,5 & 4,5 & - & Organic depression & $\mathrm{IM} / \mathrm{DZ}$ \\
\hline 9 & Idiopathic & $\mathbf{F}$ & 57 & 3 & - & 22 & 2 & 6 & + & $\begin{array}{l}\text { Severe endogenous } \\
\text { depression }\end{array}$ & $\mathbf{A T} / \mathbf{D Z}$ \\
\hline 10 & Idiopathic & $\mathbf{M}$ & 58 & 12 & - & 22 & 16 & 5 & + & $\begin{array}{l}\text { Severe endogenous } \\
\text { depression }\end{array}$ & IM/DZ \\
\hline 11 & Idiopathic & $\mathbf{M}$ & 68 & 5 & - & 16 & 10 & 2 & + & Endogenous depression & $\mathrm{DZ}$ \\
\hline 12 & Atherosclerotic & $\mathrm{F}$ & 74 & 5 & - & 24 & 7 & 4,5 & - & Acute confusional & $\mathrm{AT} / \mathrm{DZ}$ \\
\hline 13 & Atherosclerotic & $\mathbf{F}$ & 84 & 2 & - & 25 & 8 & 4 & - & Delusional episodes & $\mathrm{DZ}$ \\
\hline 14 & Idiopathic & $\mathrm{F}$ & 54 & 7 & + & 11 & 3,5 & 3 & + & $\begin{array}{l}\text { Severe hypochondrial } \\
\text { neurosis/depression }\end{array}$ & $\mathbf{A T} / \mathbf{D Z}$ \\
\hline 15 & Idiopathic & $\mathbf{M}$ & 69 & 14 & + & 15 & 9 & 3,5 & + & Organic depression & IM/P \\
\hline
\end{tabular}

*At the appearance of disturbances.

†Prescribed after onset of disturbances: $\mathbf{A T}=$ amitriptyline; $\mathbf{I M}=$ imipramine; $\mathbf{N T}=$ nortriptyline; $\mathbf{D Z}=$ diazepam; $\mathbf{P}=$ probamate $\mathbf{T H}=$ thioridazine. 
endogenous depression who had been admitted to treatment during a normal phase. He was not on psychiatric drugs at the time of admission or during treatment with L-dopa. He became mildly depressed but his clinical picture changed often and seemed to improve; no psychiatric treatment was prescribed. He had had a prodrome before, on a dose of $4 \mathrm{~g} /$ day after a month of treatment but he became normal with reduction of L-dopa and so the dosage was increased once again. It was only four months later that the acute episode described above occurred. Subsequently, he was admitted to hospital with severe anxious and inhibited depression. Amitriptyline $(100 \mathrm{mg} /$ day $)$ and diazepam $(60 \mathrm{mg} /$ day $)$ were given and L-dopa was increased to $6 \mathrm{~g} /$ day. The neurological condition which had worsened concomitantly, improved once more and he became free of depressive symptoms.

Another peculiar case (no. 4) was that of a 68 year old man with moderate depressive symptoms. On a dosage of 4 to $5 \mathrm{~g} /$ day, there was sudden increase of his feelings of sadness which he was able to verbalize for a while and then developed a state of mutism, depressive expression, and complete motor inhibition. The reduction of dose (to $2 \mathrm{~g} /$ day) combined with the administration of nortriptyline was followed by total remission of the picture.

Case 13 developed visual hallucinations and false interpretations in a state of clear consciousness and balanced mood. The content of the delusive phenomena was not paranoid and did not influence an otherwise normal mental state. These symptoms first appeared on a dosage of $4.5 \mathrm{~g}$ L-dopa daily and subsided only when it was lowered to $1.5 \mathrm{~g} /$ day.

As mentioned before, an acute confusional state developed in a woman patient of 78 years old (case 1) on $3 \mathrm{~g} /$ day, with no previous psychiatric disturbance.

No acute case relapsed or recurred, which may be attributed to the caution used in L-dopa dosage and to the other medication then prescribed.

NON-ACUTE DISORDERS Previous symptomatology worsened in seven cases. One of them (case 6) was a depressive syndrome of long standing, mainly reactive in origin, in a woman of 73 with no atherosclerotic troubles. She became markedly worse after a month of L-dopa on $3 \mathrm{~g} /$ day, increasing her experience of reactive sadness.

In the other cases, organic and endogenous factors were the more relevant. In the organic depressive syndromes (cases $7,8,15$ ), anxiety and emotional lability were the prominent common features along with motor inhibition, apathy, and lack of interest in treatment. In the endogenous depressive syndromes (cases 9, 10, 11), anxiety and experiences of vital sadness were very marked and somatic complaints increased. Body discomfort was experienced with great suffering and was the basis for more structured melancholic delusions.

The most remarkable aspect of some of these cases was the clear-cut difference between the excellent neurological improvement and the psychological worsening. Patients were incapable of recognizing the astonishing progress that had been made possible in their lives; they fought actively against the drug which was felt to be the cause of discomfort. Also, the neurological improvement tended to be interrupted occasionally after peaks of depression. We think this happens often enough to be evident even if it is impossible to identify a consistent pattern for its occurrence.

PSYCHOLOGICAL CHANGeS Not all the psychiatric effects of L-dopa are as dramatic as the above. Many patients exhibited several subtle alterations which did not hamper their rehabilitation. Discomfort was not unbearable and allowed them to prefer L-dopa to former drugs.

1. Realization of a state of previous disease Several patients described an 'awakening from torpor', with a sense of amazement at their newly acquired $\stackrel{\odot}{\sigma}$ capacities, and recognition of the severity of their previous condition. This is particularly marked in patients who have been well compensated by under- $\varrho$ standing relatives who have carefully avoided the total revelation of the disablement. It is often this very type of relative who, enthusiastic about the patient's improvement, stress that 'paralysis and incapacity are finally over', thus changing their attitudes towards the illness. On the other hand, the natural compensation that leads many patients to ignore the more negative aspects of their condition and protect their self-images tends to disappear. To an intelligent patient the handling of this evolution is not trivial and we have given particular attention to this aspect.

2. Apprehension and arousal states Some patients have mentioned a state of almost permanent arousal, described as a 'mute tension'. One of the patients with the best neurological results stated: 'It is as if I were always on the eve of a trip or some big event; nervous but cheerful.' Another patient without apparent signs of disease referred to 'a thin nervousness that doesn't let me stop; I am more capable now but I had a quieter life before L-dopa'.

These are common remarks at one stage or another of the treatment but in some patients, like those quoted above, it becomes a relatively stable feeling. In several reports we find a type of experience akin to Kurt Conrad's well-known description 
of 'trema' (especially in cases where a depressive or neutral mood is present as well).

Concerning mood changes, we do not think Ldopa is responsible for the induction of true euphoria It certainly increases arousal, which, combined with an elated mood, may produce a picture of euphoria or in a patient with depressive feelings, may resemble an acute dysthymia.

3. Mood spells In some patients we were able to detect a variation of mood in daytime. This variation had the following characteristics: (a) sudden onset of a state of intense mental and physical wellbeing, with decrease of anxiety and arousal; (b) motivation for movement and human contact resulting in the accomplishing of often neglected tasks; (c) experience of motor improvement; (d) objective neurological improvement as measured by the Webster score; (e) variable duration of these periods, from a few minutes to several hours; (f) variable duration of the intercritical period.

In some patients a given pattern of variation became relatively stable for some periods. In most of them this type of alteration tended to vary or at least to change greatly both in the number and frequency of periods.

As described by the patients the phenomena (like 'spells' and 'crisis', which are generally welcome) look primarily like a 'tidal' positive fluctuation of mood and motivation affecting the whole person and strongly improving motor behaviour. The close connection between psychological improvement and neurological improvement is very dramatic and there is no counterpart for this in Parkinsonism treated with the classical drugs. However, these phenomena recall the peculiar aspects of paradoxical akinesia and of the blocking of motor performance, described in Parkinsonism (with or without treatment) and deserve attention.

\section{THERAPEUTIC ASPECTS}

1. DRUGS No patient was put on psychotropic drugs unless his condition made them absolutely necessary (we exclude the eventual use of hypnotics).

All cases of depressive syndrome were treated with tricyclic antidepressants (amitriptyline, imipramine, and in one case nortriptyline). We did not have any case of blood pressure disturbance and we do not think that the fear of some authors is warranted concerning the combination of L-dopa and tricyclic antidepressants. With the usual effective dose ( 75 to $125 \mathrm{mg} /$ day), the thymoleptic response comes within the expected period and terminates the syndrome as satisfactorily as in a patient without Parkinsonism.
The use of very low doses of antidepressant drugs (apparently justifiable for reasons such as old age, poor general condition, etc.) seems inconvenient because the antidepressant effect is rather difficult to obtain. Also, if a patient receiving these ineffective low doses is also having classical anti-Parkinsonism drugs, the summation of anticholinergic effects is generally unbearable. We tried desipramine in only two cases. The reference to its anti-Parkinsonism action in well controlled trials (Laitinen, 1969), combined with the antidepressant effect, made it very attractive. However, the effect of provoking anxiety was so marked that it called for very low dosage and we abandoned it. It is probable that a judicious use of anxiety-reducing drugs may produce some better results. We did not use monoamine oxidase inhibitors. For the treatment of anxiety we tried, for some months, probamate (800 to 1200 $\mathrm{mg} /$ day), but this is not always strong enough. Diazepam was very effective and no patient showed neurological deterioration. The possibility of employing this drug without restrictions is quite relevant because in the acute anxiety states or in acute psychotic states diazepam may be administered in high doses (50 to $70 \mathrm{mg}$ daily) along with the reduction or suspension of L-dopa.

The use of neuroleptics should in principle be reserved for emergencies that cannot be handled otherwise. The acute psychotic cases can be managed with reduction or suspension of L-dopa as mentioned above. Treatment can be resumed shortly after the acute phase is over, starting with lower L-dopa dosage and increasing it slowly and cautiously.

2. PSYCHOTHERAPY With the exception of rare cases with indication for specialized types of psychotherapy, medical action is based on a firm support of the individual personality. It is important that the patient should so far as possible accept his situation of deficit, strengthening his capacity to face the scrutiny and appreciation of normal people, enabling him to perform tasks in public with minimum fear of ridicule and unfavourable opinions. It is also important to encourage the patient to follow regular therapeutic schedules especially with regard to physiotherapy. Though apparently simple, this implies an enduring and not always successful effort demanding intense collaboration from all around the patient. L-dopa has significantly changed the responsiveness to psychotherapy. Patients often feel that the 'progress of the disease' has stopped as well, and this enables the doctor to reinforce the notion of 'hope for recovery'. On the other hand, new problems are posed by the psychological side-effects 
of L-dopa, in particular anxiety and the experience of physical discomfort.

\section{DISCUSSION}

It is widely accepted that L-dopa is responsible for psychiatric disturbances but only recently have these been subjected to a separate psychiatric study. Our results are in general close to those of Jenkins and Groh (1970), and Celesia and Barr (1970). Jenkin's percentage of disorders is $24 \%$ (21 out 90 ) and the clinical pictures he describes are roughly the same as ours. He records four cases of suicide of which we have none. Celesia's results are rather different, possibly due to the greater number of atherosclerotic and post-encephalitic patients in his series. Our case 13 resembles some of his cases of psychosis in atherosclerotic Parkinsonism with visual hallucinations and illusions in a state of normal consciousness.

We agree with Sacks et al. (1970) that patients with dementia are a bad risk. In our group 3 patients with demential pictures and organic depression became worse. However, three other patients with relatively similar conditions have been treated without trouble.

The problem of depression has been given particular emphasis as it is so common in Parkinsonism and claims have been made for a euphoriant action of L-dopa.

We consider that an antidepressant action of L-dopa is very improbable. We did register an improvement in patients with reactive depression but attribute this to the neurological improvement combined with a moderate excitatory effect.

Most patients with a previous psychiatric history involving endogenous or organic factors became worse or developed new symptoms, even if neurological improvement were good. Indirectly L-dopa did improve some forms of depression. In our experience L-dopa combines very safely with tricyclic antidepressants, allowing the latter's usual action and, in some cases, probably accelerating it. Goodwin, Brodie, Murphy, and Bunney (1970), treated nine cases of depression with L-dopa and only three showed relative improvement and the experience of Matussek, Benkent, Schneider, Otten, and Pohlmeier (1970) was similar.

Such clinical results have their experimental counterpart. It has been established that the administration of L-dopa to higher mammals determines serious abnormalities of behaviour by activation of the dopaminergic systems in the corpus striatum resembling in its general action the effect of amphetamines and apomorphine (Randrup, 1967, 1970). This is very important, because the laboratory- induced disorders can be corrected by neuroleptics which will in turn produce extrapyramidal symptoms (Rossum, 1967).

The results of this study may be summarized as follows.

The expectation of psychiatric disorders precipitated by L-dopa in a random population with Parkinson's disease increases with the previous existence of ongoing psychiatric process, former psychiatric episodes, or a familial psychiatric history. The risk is high if the history includes any psychosis with endogenous or organic basis.

Acute disturbances may be forecast and some of them avoided by watching carefully the sleep/ vigilance rhythm and the level of anxiety shown by the patient. The onset of persistent insomnia resisting barbiturate action plus an increase in the level of anxiety should be considered a prodrome of acute psychosis. L-dopa dosage should then be lowered and tranquillizers increased.

After the onset of psychosis the suspension of L-dopa and the administration of high doses of tranquillizers should precede the use of neuroleptics which may be used as a last emergency resort if these measures are not effective.

The course of the depressive syndromes in our group showed at least two markedly different patterns of reaction to L-dopa. The fact that these patterns grossly correlate with an aetiopathogenic division of cases between reactive and endogenous/ organic supports, in our view, the validity of this distinction.

Special attention should be given to the psychological well-being of patients. Neurological capacity is often a function of psychological balance. These factors are very closely interdependent, as is shown by phenomena like paradoxical akinesia or the blockade of motor performance.

\section{REFERENCES}

Barahona-Fernandes, H. J. (1970). Psychopharmacodynamie des neuroleptiques. Effets d'organisation sur les syndromes paranoïdes. Int. Pharmacopsychiat., 3, 94-118.

Barbeau, A. (1969). L-dopa therapy in Parkinson's disease. A critical review of nine years' experience. Canad. med. Assoc. J., 101, 791-800.

Calne, D. B., Stern, G. M., Laurence, D. R., Sharkey, J., and Armitage, P. (1969). L-dopa in postencephalitic parkinsonism. Lancet, $1,744-747$.

Calne, D. B., Spiers, A. S. D., Stern, G. M. Laurence D. R., and Armitage, P. (1969a). L-dopa in idiopathic parkinsonism. Lancet, 2, 973-976.

Celesia, G. G., and Barr, A. N. (1970). Psychosis and other psychiatric manifestations of levodopa therapy. Arch. Neurol. (Chic.), 23, 193-200.

Cotzias, G. C., Papavasiliou, P. S., and Gellene, R. (1969). Modification of parkinsonism-chronic treatment with L-dopa. New Engl.J. Med., 280, 337-345.

Damásio, A. R., Lobo Antunes, J., and Macedo, C. (1970). L-dopa, parkinsonism, and depression. Lancet, 2, 611-612. 
Goodwin, F. K., Brodie, H. K. H., Murphy, D. L., and Bunney, W. E., Jr. (1970). Administration of a peripheral decarboxylase inhibitor with L-dopa to depressed patients. Lancet, 1, 908-911.

Hoehn, M. M. and Yahr, M. D. (1967). Parkinsonism: onset, progression, and mortality. Neurology (Minneap.), 17, 427-442.

Jenkins, R. B., and Groh, R. H. (1970). Mental symptoms in Parkinsonian patients treated with L-dopa. Lancet, 2, 177-180.

Laitinen, L. (1969). Desipramine in treatment of Parkinson's disease. A placebo-controlled study. In Third Symposium on Parkinson's Disease, pp. 173-176. Edited by F. J. Gillingham and I. M. L. Donaldson. Livingstone: Edinburgh.

Lobo Antunes, J., Macedo, C., and Damásio, A. R. (1971). Report to the Portuguese Society of Neurology and Psychiatry, October. Médico (Porto), 59, 443-464.

Matussek, N., Benkert, O., Schneider, K., Otten, H., and Pohlmeier, H. (1970). L-dopa plus decarboxylase inhibitor in depression. Lancet, 2, 660-661.

McDowell, F., Lee, J. E., Swift, T., Sweet, R. D., Ogsbury, J. S., and Kessler, J. T. (1970). Treatment of Parkinson's syndrome with $\mathrm{L}$ dihydroxyphenylalanine (levodopa). Ann. int. Med., 72, 29-35.

Mettler, F. A., and Crandell, A. (1959). Relation between Parkinsonism and psychiatric disorder. J. nerv. ment. Dis., 129, 551-563.
Randrup, A. (1970). Role of brain dopamine in the antipsychotic effect of neuroleptics. Evidence from studies of amphetamine-neuroleptic interaction. Mod. Probl. Pharmacopsychiat., 5, 60-65.

Randrup, A., and Munkvad, I. (1967). Stereotyped activities produced by amphetamine in several animal species and man. Psychopharmacologia (Berl.), 11, 300-310.

Rossum, J. M. van (1967). The significance of dopaminereceptor blockade for the action of neuroleptic drugs. International Congress Series No. 129. Excerpta Med. (Amst.), 321-329.

Sacks, O. W., Messeloff, C., Schwartz, W., Goldfarb, A., and Kohl, M. (1970). Effects of L-dopa in patients with dementia. Lancet, 1, 1231.

Schwab, R. S., and Zieper, I. (1965). Effects of mood, motivation, stress and alertness on the performance in Parkinson's disease. Psychiat. Neurol., 150, 345-357.

Talland, G. (1962). Cognitive functions in Parkinson's disease. J. nerv. ment. Dis., 135, 196-205.

Waggoner, R. W. (1967). In Comprehensive Textbook of Psychiatry. Edited by A. M. Freedman and H. I. Kaplan. Williams and Wilkins: Baltimore.

Webster, D. D. (1968). Critical analysis of the disability in Parkinson's disease. Mod. Treat., 5, 257-282.

Yahr, M. D., Duvoisin, R. C., Schear, M. J., Barrett, R. E., and Hoehn, M. M. (1969). Treatment of Parkinsonism with levodopa. Arch. Neurol. (Chic.), 21, 343-354. 